\title{
An Attempt to Use the Results of Microtomographic Studies of the Surface After the Period of Operation in the Numerical Analysis of Wheel-Rail Contacts
}

\author{
Henryk BĄKOWSKI*, Antoni JOHN**, Jarosław BRODNY*** \\ *Silesian University of Technology, Faculty of Trasnport, Krasińskiego 8, 40-019 Katowice, Poland \\ E-mail: henryk.bakowski@polsl.pl \\ **Silesian University of Technology, Faculty of Mechanical Engineering, Konarskiego 18A, Gliwice 44-100, Poland, \\ E-mail: antoni.john@polsl.pl \\ *** Silesian University of Technology, Faculty of Organization and Management, Roosevelta 26-28, 41-800 Zabrze, \\ Poland, E-mail: jaroslaw.brodny@polsl.pl
}

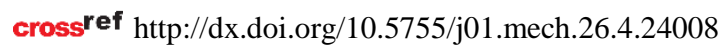

\section{Introduction}

During the contact of two bodies, their interaction causes an increase in stress and thus an increase in surface energy. Therefore, this energy, depending on the type of material, can cause physicochemical changes in it, which in turn lead to the phenomenon of decohesion. In order for the phenomenon to occur, it must be exceeded the limit of strength of the material is usually the yield point. Depending on the material's properties (especially hardness) the time in which contact surfaces stay in contact is extremely important because the longer it is, the more energy will be transferred to the other body. In the case of materials with a high hardness, the energy is first converted into elastic and then plastic impacts, causing plastic deformation and dislocation motion, leading to the separation of material layers and its defect. However, much more plastic materials are faster than the yield point and the separation of material in the form of flaky wear debris.

The occurring processes of wear of metal parts of machines different from each other by special features and the mechanism of wear development. The image of the top layer wear differs from each other: the appearance of the friction surface, structural changes of the surface layer material, mechanism of destroying the surface layer material, the shape and dimensions of wear debris and their composition.

The reasons for the recall of the product from further services may vary, with abrasive and/or adhesive or fatigue being the most important, followed by other types of wear. The pressure of the wheel causes the material on the rolling surface to begin to move, i.e. "flow", and the resulting permanent deformations lead to the formation of patchy wear products. As the number of cycles increases, the flakes formed can lead to fatigue cracks. This process is called ratchetting [1]. Ratchetting consists in accumulating deformation, in the main direction of load displacement, in the course of consecutive cycles (Figs. 1, 2). According to the dislocation theory of defects, stress concentrators are clusters of dislocations that form after encountering obstacles. The increase in stresses results in the generation of new dislocations, which move as a result of exceeding the yield point. As a result of mutual blocking of dislocating dislocations and the presence of atoms of dopants of alloying elements, gradual strain strengthening occurs. In work [2] authors presented a new twodimensional plain strain rough wheel/rail contact model is developed which includes stick-slip phenomena of the realistic contact situation and is related in a mechanically justified way to the three-dimensional situation. Appearing the small rough areas causes pick of the stresses in surface layer. The presented research allows to determination the distribution of stresses and their depth in subsurface layer and how appear the wear debris. In this way we can characterisation of wear type [3].

\section{Rolling-sliding contact characterization}

When the wheels roll on rails, both the wheel and the rail are deformed and the point of their contact changes into a certain area. For a perfectly contoured surface of the wheel and head of the rail, the contact area is an ellipse. When the wheel is rolling on a rail, parts of this area are in contact with the rail and a slip on the part. These forces distributed over the contact area appear as stresses, while the distribution of tangential stresses depends on the shape and size of the area, the values of slip and the condition of the rolling surfaces. The wheel rolling on the rail rests on a small surface, the field of which is from 100 to $150 \mathrm{~mm}^{2}$ depending on the profile and the degree of wear of the running surface of both the wheel and rail [3].

The final result is the detachment of the surface layer material from the rolling surface (Fig. 1).

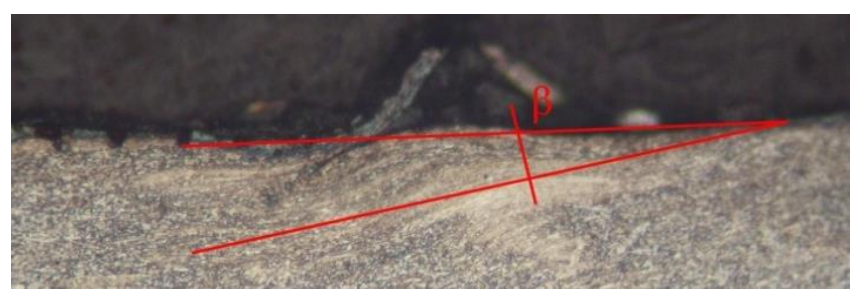

Fig. 1 Top layer with visible turning off wear debris (the zone is textured at a right angle)

The normal stresses caused by the local pressure of the wheels often cause the yield point to be exceeded below the running surface of the rail head. This statement is correct in the case of the theory of wear developed by Suha in the process of rolling and sliding friction. Irreversible changes on the surface of the material and just below it arises as a result of the concentration of stresses 
usually located under the surface of the material, at a certain depth, resulting in separation of the material. The basic condition for low-fatigue fatigue cracks is the presence of cyclic plastic deformations. The work of plastic deformation during one cycle determines the area limited by the hysteresis loop. Part of this work goes to the material, causing changes in structure, while the rest is dissipated as heat. In the initial stage of cyclic loading there is a change in material properties which, depending on its type and load conditions, can be subject to cyclic strengthening of deformation or cyclic deformation weakening. After a relatively small number of load cycles (often <100), the properties stabilize and the material acquires a constant resistance to cyclic stresses or cyclic deformations [4].

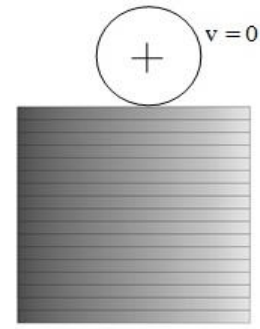

a

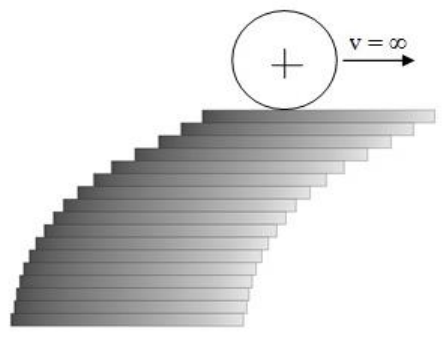

b
Fig. 2 Scheme of the surface layer of the rail: a) before operation, b) after operation [2]

\section{Experimental details}

Numerical simulations and tests using a computer microtomograph will allow locating the places most exposed to wear and damage depending on various operating conditions. Tribological tests were conducted on an Amsler testing machine. The device, with a tribological couple of a roller-roller type, serves for testing wear in case of rolling friction, sliding friction or a combination of both. To determine the values of forces acting in laboratory conditions in relation to the real conditions, the theory of similitude was applied in the wheel-rail system and formula (1) was used, assuming geometrical similarity of the friction couples under consideration [6]:

$$
\frac{P^{\prime}}{R^{\prime} \cdot L^{\prime}}=\frac{P}{R \cdot L} ;\left(\frac{N}{m^{2}}\right)^{\prime}=\left(\frac{N}{m^{2}}\right)
$$

where: $P^{\prime}$ and $P$ - load in laboratory conditions and in a real object, in $\mathrm{N} ; R^{\prime}$ and $R$ - substitute radius in laboratory conditions and in a real object, $R=\frac{R_{1} \cdot R_{2}}{R_{1}+R_{2}} ; L^{\prime}$ and $L-$ substitute radius in laboratory conditions and in a real object, in $\mathrm{m}$.

This way, the values of forces, and consequently, of stresses formed in the rolling-sliding contact in the friction couple were determined. By comparing the compressive stresses formed in the contact zone during rollingsliding friction of two interacting components in both a real and laboratory object (1), it is possible to map with a rough approximation the conditions present in both friction zones (Table 1).

Table 1

List of stress values depending on the type of system

\begin{tabular}{|c|c|c|c|}
\hline \multicolumn{2}{|c|}{ Load in conditions } & $\begin{array}{c}\text { Stress in wheel-rail contact } * \\
\sigma_{u}, \mathrm{MPa}\end{array}$ & $\begin{array}{c}\text { Stress in a roller-roller system on laboratory stand } * \\
\sigma, \mathrm{MPa}\end{array}$ \\
\hline real object & laboratory stand & 836 & 875 \\
\hline $100 \mathrm{kN} /$ wheel & $2 \mathrm{kN}$ & 836 & 8 \\
\hline
\end{tabular}

*Hertz formula

Strengthening the rail material, after a longer period of track exploitation, causes its degradation, contributing to the fatigue cracks of the rail. At the same time, plastic "flow of material" appears as a result of the tangential stress. The material "flows" along the rail in the direction of the rolling wheel and in the transverse direction towards the running edge of the rail (Fig. 3).

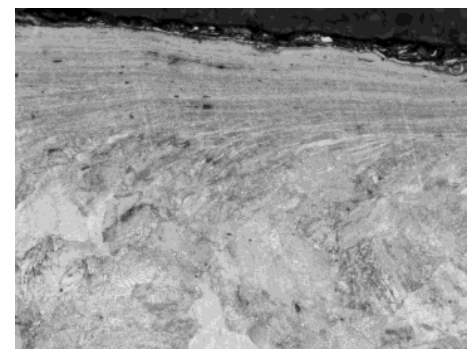

area of ratchetting

area of plastic-elastic deformations

area of elastic deformations

Fig. 3 Cross-section of the surface layer of the rail after operation

The phenomenon of wear occurring in a rollingslip contact always has the form of wear debris, the size and shape of which is determined by variable operating factors, type of treatment (thermal or plastic) and condition and properties of the surface layer of the material. Howev- er, in order to fully correlate the relationship between wear and durability, all the significant types of stresses that occur in the rail under the influence of variable interactions should be considered [5].

One of the tasks undertaken in this paper is an attempt to explain the cause and effect relationship of operating parameters to the wear of the wheel/rail contact zone in which fatigue processes are initiated. To obtain a faithful reflection of the friction surface, the following procedure was used (Fig. 4).

Data import from a computer microtomograph can be performed using a free tool, ie the FIJI program. The possibilities of this program allow you to save the image obtained from the microtomograph in a lossless (*.raw) format to (*.stl) format. In the GMSH program, the geometric model allows you to generate a mesh mesh and export to a MES solver (MSC.Marc). The subject of numerical simulations is the analysis of the state of stresses in the contact zone for the real contact surface (after cooperation) in the following sets of tests:

a) analysis of friction surface after cooperation (deformable) and perfect deformable surface,

b) analysis of friction surface after cooperation (deformable) and rigid ideal surface (rigid). 


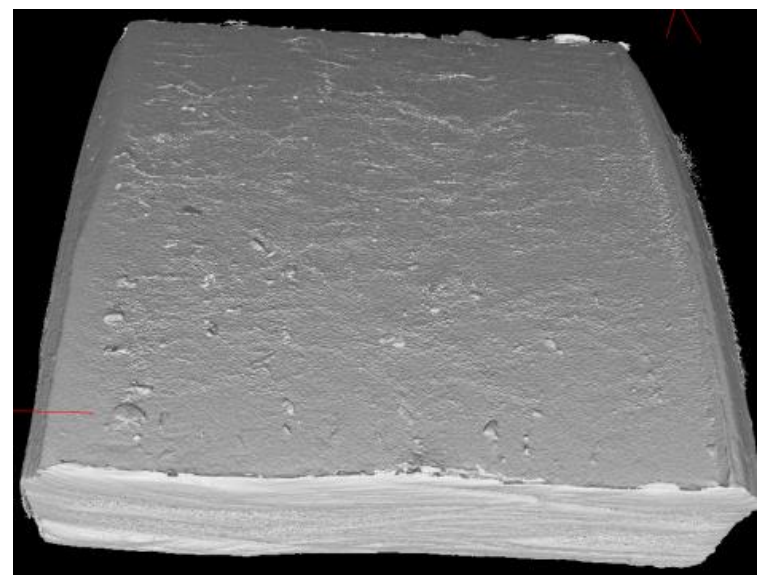

a

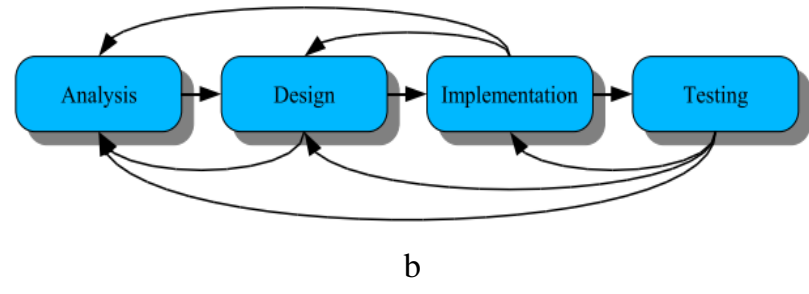

Fig. 4 The real surface layer obtained in laboratory test by Computed Tomography (Nanotom S) (a) and stages of project (b)

Data import from a computer microtomograph can be performed using a free tool, ie the FIJI program. The possibilities of this program allow you to save the image obtained from the microtomograph in a lossless (*.raw) format to (*.stl) format. In the GMSH program, the geometric model allows you to generate a mesh mesh and export to a MES solver (MSC.Marc).

The capabilities of the FIJI ImageJ program are quite extensive and advanced. The software allows viewing, editing, processing or printing graphics of both 8, 16 and 32-bit graphics. ImageJ allows you to open images saved in commonly used and popular formats (such as TIFF, RAW, GIF, JPEG, BMP, PNG, PGM, ASCII). In addition, the DICOM (Digital Imaging and Communications in Medicine) recording system is supported, used in medical imaging, or FITS (Flexible Image Transport System) found in the field of astronomy, used, among others, by NASA or IAU. The great advantage of the program is its speed, which, with very large files, is of great importance to users who often use "weaker" computers. Summing up, you can successfully use the program dedicated primarily to medical applications and use in the broadly understood technical industry (Fig. 5).

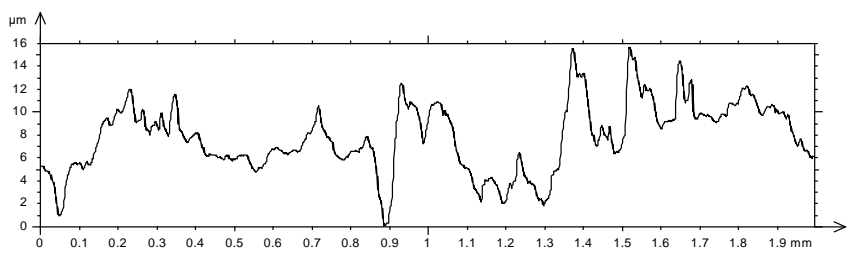

Fig. 5 Roughness profile 2D

The subject of numerical simulations is the analysis of the state of stresses in the contact zone for the real contact surface (after cooperation) in the following sets of tests:

a) analysis of friction surface after cooperation (deformable) and perfect deformable surface,

b) analysis of friction surface after cooperation (deformable) and rigid ideal surface (rigid).

In addition, for the purpose of comparison, simulations of the system were also carried out in the case of cooperation of ideal surfaces (smooth - with no signs of wear) for the case of two deformable bodies and a deformable and rigid body. The analysis of the state of stress and strain in the contact zone for the friction surface after cooperation (both worn surfaces, deformable) is being prepared. The tests were carried out using the MSC.Marc program to determine the distribution of stresses in the surface layer. On figure presented the real surface topography which were mapped in simulation tests by means of FEM (Fig. 6, 8f).

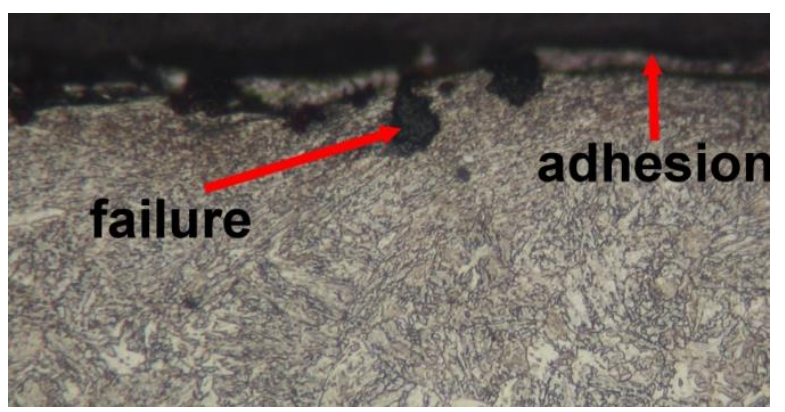

Fig. 6 The real surface topography on metallographic specimen

\section{Numerical simulations}

Appropriate models of the analyzed machine parts have to be built if FEM is to be effectively applied. Therefore, the user should undertake the following activities like pre and postprocessing.

In addition, numerous contaminants, very common in the Upper Silesian Industrial Region, can accumulate on the surface of the rail. One of them is a wide range of different organic pollutants were identified [8]. A number of these compounds are present in coal, coal wastes, and coal tar, as well as in vehicle emissions or fly ash derived from combustion. The accumulation of these compounds on the surface of railway rails may cause a change in the coefficient of friction or wear mechanism. Therefore, the proposed factors should be tested in the future.

The analyzed model was a section of the friction surface with a width of $1.9 \mathrm{~mm}$ and a height not exceeding $16 \mu \mathrm{m}$. The tests were performed for $2 \mathrm{D}$ and $3 \mathrm{D}$ models. The MSC.Software/Marc system was used for numerical analysis. A non-linear calculation was performed. Rail material with the following material coefficients was assumed: Young's modulus $E=210000 \mathrm{MPa}$ and Poisson's ratio $v=0.3$ and a density $\rho=7900 \mathrm{~kg} / \mathrm{m}^{3}$. The detailed boundary conditions are illustrated in Fig. 7. In the 2D research 2757 nodes and 11642 shell elements were used to build the model. 3D numerical model was built using 212896 elements and 46989 nodes. Mesh type is mix of bricks, wedges, pyramids and tetrahedral.

In order to compare the obtained results, a model with a real contact surface and a flat surface was used (Fig. 7). 


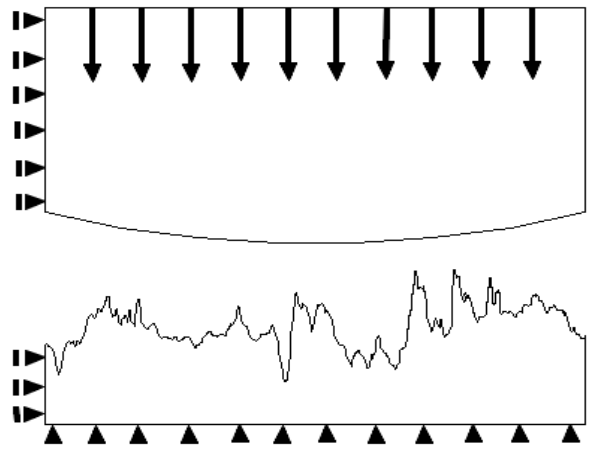

a
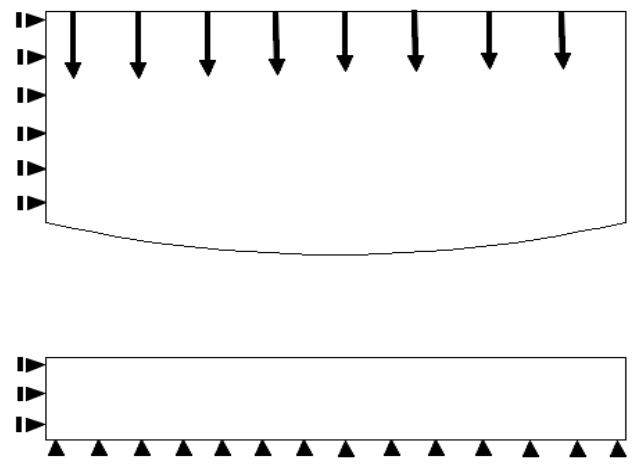

$\mathrm{b}$

Fig. 7 Boundary conditions: a) real contact surface, b) flat contact surface

\section{Results}

The main objective of the research was to determine the actual contact area and the relationship between the analyzed friction surface and its susceptibility to mechanical damage. This is of particular importance as the analyzed wear processes form differently on the actual contact surface than is the case for analyzes of ideal surfaces with isotropic material properties. An important part of the research is the attempt to locate the most vulnerable places depending on various operating conditions and to identify the basic mechanisms of wear. As a result of the FEM analysis, the results of simulation tests are presented on Fig. 8. Tables 2, 3 presents a summary of the obtained results.

In real working conditions of the wheel-rail assembly, there are stresses and slips affecting the processes occurring in this important place in the place of contact. The contact surface is permanently changed depending on many factors, both construction and operation. As a result of the overlap of these factors, the problem of durability of the surface layer, especially the running surface of railway rails, remains unsolved. Currently, the biggest problem is to maintain the balance between abrasive wear (vertical and lateral wear - occurring in railway rails) and fatigue wear, which occurs in the form of contact-fatigue damages leading to cracks on the surface and even transverse cracks.

Table 2

Reduced Huber-Mises stress (MPa) and surface depth $(\mu \mathrm{m})$

\begin{tabular}{|c|c|c|c|}
\hline \multicolumn{4}{|c|}{ 2D model: Reduced Huber-Mises stresses $\sigma_{z}, \mathrm{MPa} / \mathrm{stress}$ depth $d, \mu \mathrm{m}$} \\
\hline \multicolumn{2}{|c|}{ Worn surface } & \multicolumn{2}{|c|}{ Flat surface } \\
\hline Rigid/Deformable & Deformable /Deformable & Rigid/Deformable & Deformable /Deformable \\
\hline $2242 / 12$ & $2164 / 25$ & $753 /-$ & $695 /-$ \\
\hline \multicolumn{4}{|c|}{ 3D model: Reduced Huber-Mises stresse [MPa]/surface depth $[\mu \mathrm{m}]$} \\
\hline \multicolumn{2}{|c|}{ Worn surface } & \multicolumn{2}{|c|}{ Flat surface } \\
\hline Rigid/Deformable & Deformable /Deformable & Rigid/Deformable & Deformable /Deformable \\
\hline $3368 / 6$ & $2368 / 10$ & $851 /-$ & $823 /-$ \\
\hline
\end{tabular}

Table 3

Selected operational parameters for the chosen railroad surface

\begin{tabular}{|c|c|c|}
\hline \multirow{2}{*}{ Tests type } & Operational parameters & Reduced stress \\
\cline { 2 - 3 } & Load $Q, \mathrm{~N}$ & $\sigma_{z}, \mathrm{MPa}$ \\
\hline \multirow{2}{*}{ Laborato- } & $P_{1}=500$ & 437 \\
ry stand & $P_{2}=1000$ & 618 \\
\cline { 3 - 3 } & $P_{3}=2000$ & 875 \\
\hline In wheel- & $Q_{1}=2,00 \cdot 10^{4}$ & 408 \\
rail sys- & $Q_{2}=6,25 \cdot 10^{4}$ & 661 \\
tem & $Q_{3}=10,00 \cdot 10^{4}$ & 836 \\
\cline { 3 - 3 } & & \\
\hline
\end{tabular}

For $P$ and $Q$ :

1 - rail load during the ride of an empty freight train;

2 - rail load during the ride of passenger train;

3 - rail load during the ride of a fully loaded freight train;

Given velocities refer to speed limits in Poland.
For the surface of worn and deformable friction the stress values were lower than for the surface of the rigid type. This is related to the larger contact surface and the plastic deformation of both surfaces. However, the depth of residual stress is almost twice as high as for contact with rigid material. The depth of retention is strictly correlated with the thickness of the patches of wear products that break off from the friction surface due to the influence of operating factors [cellar]. Considering the flat surface of cooperation, no micro-friction processes can be observed [7]. All aspects of the wear process should be considered on a micro scale, i.e. using the nomenclature of the socalled - microtribology. The simulation tests were carried out of the preliminary studies. The use of elastic material model allowed to present the mechanism of wear and processes in the micro-contact. A model based on elasticplastic material would not allow determining the wear mechanism and the depth of stress occurring in the subsurface of the material. 


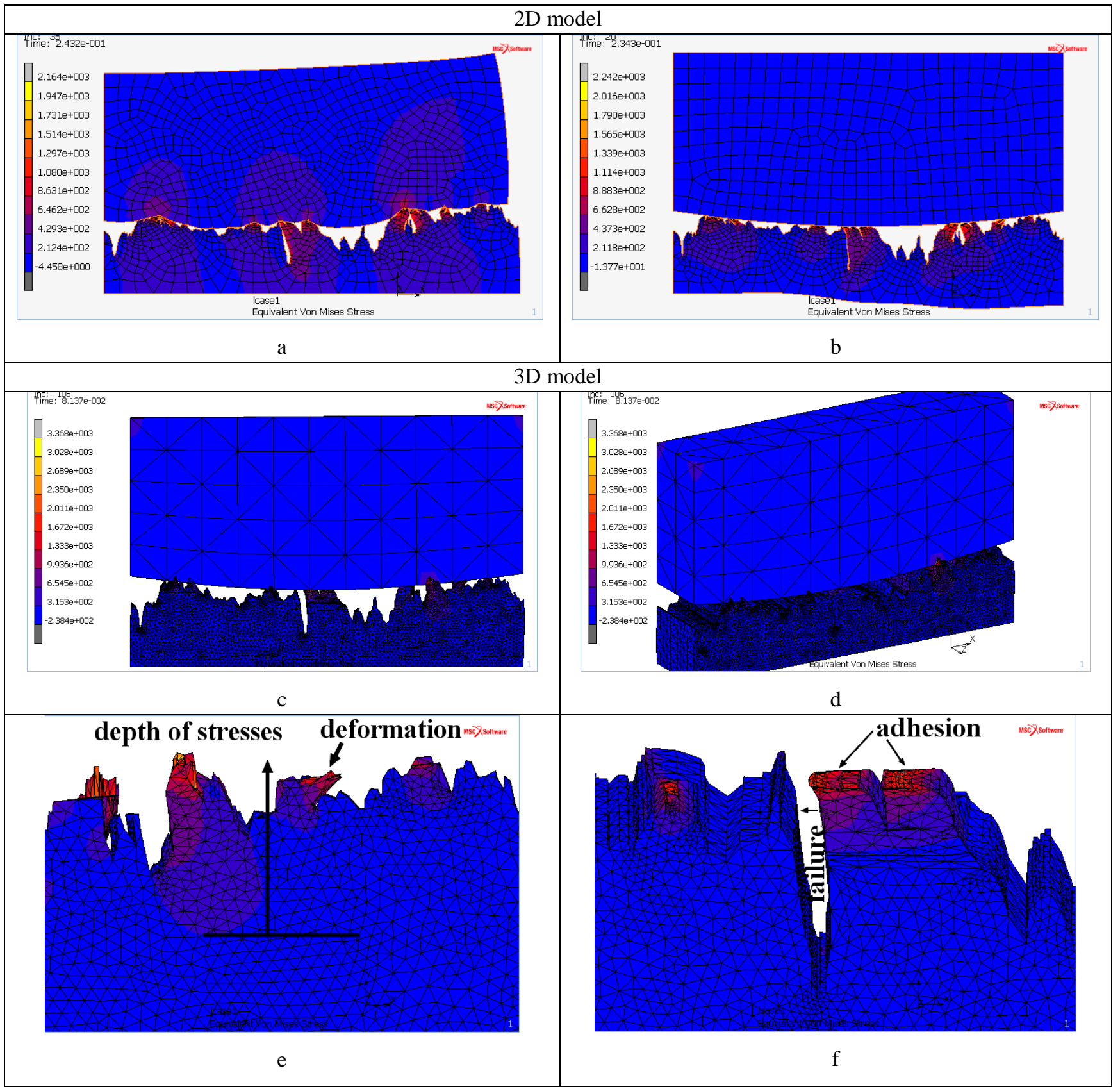

Fig. 8 Distribution of reduced Huber-Mises stresses: a) a curved surface (deformable) and surface after cooperation (deformable); b) a curved surface (rigid) and surface after cooperation (deformable); c), d) 3D model; e) probability appearing of the wear debris and measurement of the stress depth $d$; f) adhesion phenomena and fatigue wear

\section{Conclusions}

The paper presents the influence of selected exploitation factors on the condition of the surface layer through the use of simulation tests using the finite element method (FEM). The surface layer was mapped using a computer microtomograph and the influence of operational parameters on its condition was presented using simulation tests by means of FEM.

Numerical analysis allows to explain the mechanism of wear and determine local stresses values. The obtained results of operational investigations prove that cracks and spallings of the micro and macro scale appear in areas with maximum stress and deformation, there is proof in work [2]. On the basis of the conducted simulation tests, FEM was found to be the right tool used to identify the areas of special wear hazard. The method also helps to explain the wear mechanisms and determine the characterization of wear. It could be say that FEM analysis helped to recognize and explain the wear mechanisms in depend of the selected operational conditions. The determination areas of the local stresses value of allowed the prediction of wear initiating places. Analyzing the real contact surface, we received over 3 times higher stresses values than on a flat surface (Table. 2). Besides, it can be determining the depth of residual stress and correlate with the thickness of the obtained flake wear debris.

On Fig. $8 \mathrm{f}$ appearing of adhesion process, which provide to adhesion wear and fatigue wear is presented. In failure area crack which propagate to through in the material could be arise.

The main objective of the research was to determine the real contact area and the relationship between the analyzed friction surface and its susceptibility to mechani- 
cal damage. This is of particular importance as the analyzed wear processes form differently on the real contact surface than is the case for analyzes of ideal surfaces with isotropic material properties. An important part of the research is the attempt to locate the most dangerous places depending on various operating conditions and to identify the basic mechanisms of wear.

\section{References}

1. Su, X.; Clayton, P. 1997. Ratcheting strain experiments with a pearlitic steel under rolling/sliding contact, Wear 205: 137-143. https://doi.org/10.1016/S0043-1648(96)07263-8.

2. Daves, W.; Kubin, W.; Scheriau, S.; Pletz, M. 2016. A finite element model to simulate the physical mechanisms of wear and crack initiation in wheel/rail contact, Wear 366: 78-83. https://doi.org/10.1016/j.wear.2016.05.027.

3. Böhmer, A. et al. 2003. Beanspruchungen von Schienen unter statischen, dynamischen und Thermishen belastungen, Glasers Annalen 127 (3, 4): 116-130.

4. Jackson, R. 2010. An analytical solution to an archardtype fractal rough surface contact model, Tribology Transactions 1: 543-553. https://doi.org/10.1080/10402000903502261.

5. Bąkowski, H.; Piwnik, J. 2016. Quantitative and qualitative comparison of tribological properties of railway rails with and without heat treatment, Archives of Metallurgy and Materials 2(63): 469-474. https://doi.org/10.1515/amm-2016-0037.

6. Miller, L. 1983: Zastosowanie analizy wymiarowej w badaniach modeli. PWN. Warszawa. 246 p. (in Polish).

7. Bąkowski, H. 2018. Wear mechanism of spheroidal cast iron piston ring-aluminum matrix composite cylinder liner contact, Archives of Metallurgy and Materials 2(63): 481-490. https://doi.org/10.24425/118965.

8. Nádudvari, Á.; Fabianska, M.; Marynowski, L. 2018. Distribution of coal and coal combustion related organic pollutants in the environment of the Upper Silesian Industrial Region, Science of the Total Environment 628-629: 1462-1488.

https://doi.org/10.1016/j.scitotenv.2018.02.092.
H. Bąkowski, A. John , J. Brodny

\section{SELECTED ISSUES IN THE FRICTION PROCESS FOR MICROCONTACT ROLLING-SLIDING IN THE 3D MODEL OBTAINED FROM MICROTOMOGRAPH}

S u m m a r y

Under the passing train in the rail, a threedimensional state of stress is created. The mutual forces exerted by the wheel on the rail consist of the normal (vertical) and longitudinal and transverse forces of the tangential force. The vertical force has a static component derived from the weight of the rail vehicle, a quasi-static component derived from the unbalance in the curves and a random component resulting from the vibrations of the vehicle mass as a result of unevenness of the track and flange rim impacts due to serration. The distribution of tangential forces in the wheel-rail system depends on the shape and size of the contact area, the slip values and the state of the running surface (surface topography).

During the contact of two bodies, their interaction causes an increase in stress and thus an increase in surface energy. Therefore, this energy, depending on the type of material, can cause physicochemical changes in it, which in turn lead to the phenomenon of decohesion. In order for the phenomenon to occur, it must be exceeded the limit of strength of the material is usually the yield point.

Depending on the material's properties (especially hardness) the time in which contact surfaces stay in contact is extremely important because the longer it is, the more energy will be transferred to the other body. In the case of materials with a high hardness, the energy is first converted into elastic and then plastic impacts, causing plastic deformation and dislocation motion, leading to the separation of material layers and its defect. However, much more plastic materials are faster than the yield point and the separation of material in the form of flaky wear debris.

The paper presents the influence of selected exploitation factors on the condition of the surface layer through the use of simulation tests using the Finite Element Method (FEM). The surface layer was mapped using a computer microtomograph and the influence of operational parameters on its condition was presented using simulation tests by means of FEM.

Keywords: wear, microcontact rolling-sliding, FEM, tribological test, microtomography.

Received August 13, 2019

Accepted August 24, 2020 